\title{
Public science communication in Africa: views and practices of academics at the National University of Science and Technology in Zimbabwe
}

\section{Heather Ndlovu, Marina Joubert and Nelius Boshoff}

\begin{abstract}
This study of the science communication views and practices of African researchers - academics at the National University of Science and Technology (NUST) in Zimbabwe - reveals a bleak picture of the low status of public science engagement in the developing world. Researchers prioritise peer communication and pay little attention to the public, policy makers and popular media. Most scientists believe the public is largely not scientifically literate or interested in research. An unstable funding environment, a lack of communication incentives and censoring of politically sensitive findings further constrain researchers' interest in public engagement. Most NUST academics, however, are interested in science communication training. We suggest interventions that could revive and support public science engagement at African universities.
\end{abstract}

Keywords

Public engagement with science and technology; Science and media; Science communication in the developing world

Introduction

Public science communication in sub-Saharan Africa is gaining ground and increasingly getting the attention of university managers and research funders. Three examples in this regard are:

- the Development Research Uptake in Sub-Saharan Africa (DRUSSA) programme, spearheaded by the Association of Commonwealth Universities (ACU), which has been behind the move to improve accessibility and uptake of locally relevant research to inform policy and practice for national and regional development [DRUSSA, 2015];

- the Southern African Research and Innovation Management Association (SARIMA), which works with research and innovation managers to provide a platform for the promotion and facilitation of best practice in research and innovation management [SARIMA, 2015], including skills development and capacity building in the field of public science communication and engagement; and

- South Africa's Department of Science and Technology, which has launched an ambitious Science Engagement Framework designed to promote and support 
public science engagement in the country [Department of Science and Technology, 2014].

Amidst increasing calls for researchers to engage with public audiences, it is important to understand how researchers experience and respond to these demands, as well as to clarify the factors that shape their involvement [Ipsos MORI, 2001; Pew Research Center, 2009; The Royal Society, 2006; Searle, 2013; TNS $\mathrm{BMRB}, 2015]$. This is especially relevant in developing countries where researchers face particular challenges in terms of public science engagement, for example a scarcity of resources, low levels of public interest and science literacy, and a lack of institutional support [Bakyawa et al., 2013; Ekanem, 2003; Tan Wee Hin and Subramaniam, 2014; Karikari, Yawson and Quansah, 2016; Khanna, 2001].

Recognising the pivotal role of the research scientist in public science engagement, several science communication scholars have investigated the factors that support or constrain scientists' involvement. However, these studies have focused on researchers in developed world countries, such as the United States of America, Japan, the United Kingdom, Spain, Italy, Germany and France, amongst others [Agnella et al., 2012; Burchell, 2015; Jensen, 2011; Kreimer, Levin and Jensen, 2011; Peters, 2013; Pew Research Center, 2009; TNS BMRB, 2015].

Literature on science communication research in the developing world is scarce. The vast majority of empirical studies come from developed, English-speaking countries [Massarani, 2015]. In Africa, research in this field is mostly limited to studying the practice of science communication, for example:

- science cafés in Kenya [Mutheu and Wanjala, 2009];

- radio for disseminating health information in Malawi [Nyirenda et al., 2016];

- public internet terminals to support health education in South Africa [Coleman, 2012]; and

- a musical show to communicate physics, also in South Africa [Fish et al., 2016].

Research has also been done on African media coverage of science, for example genetically modified (GM) crops in Kenya [DeRosier et al., 2015] and the Square Kilometre Array project in South Africa [Gastrow, 2015].

In the African context, two studies have explored the science communication attitudes of researchers - both focused specifically on the challenges that South African scientists experience in their interactions with the mass media [Claassen, 2011; Gething, 2003].

The current study This study sought to reveal the views and practices of African researchers — university-based academics in the developing world - concerning public science communication. It looked at communication platforms and activities and the institutional environment, as well as the barriers and skills shortages that may 
impede public science communication in Africa. Using a mixed-methods approach, we surveyed and interviewed selected academics across all scholarly disciplines at the National University of Science and Technology (NUST) in Zimbabwe.

As part of its vision, NUST aims to be a world-class centre of excellence in teaching, research, innovation and entrepreneurship for sustainable development. The NUST mission states that the university strives to contribute positively towards the advancement of humanity through the provision of knowledge-based solutions to scientific, technological, economic and social challenges [NUST Yearbook, $2011 / 2012$, p. 37]. Against this background, it is interesting to ask to what extent academics at this institution are engaging with the public, and which factors support or limit their involvement.

To the best of our knowledge, this study is the first of its kind, i.e. gathering information on views and practices of academics across all disciplines and faculties at an African university.

Literature overview

As background for this study amongst African academics, we reflect briefly on how science communication literature defines and validates public science communication and engagement, followed by a short overview of existing studies concerning the participation of academics in public science communication activities, and the factors that affect their willingness and ability to be involved.

\section{What counts as public science communication and engagement?}

Science communication takes on multiple forms, takes place via a wide range of platforms and encompasses diverse models, strategies, objectives and evaluation approaches [Einsiedel, 2014; Stilgoe, Lock and Wilsdon, 2014]. As such, many scholars advocate for broad and inclusive definitions [Bauer and Jensen, 2011; Jensen, 2011; Kreimer, Levin and Jensen, 2011]. The diversity in public engagement formats are highlighted by Grand, Davies, Holliman and Adams [2015], listing between 12 and 17 public science engagement activities and up to 100 participatory activities. Strategies that scientists may use to inform and engage public and policy audiences include:

- media appearances on radio, television and in newspapers;

- public talks and debates;

- participation in science cafés and science museum events;

- workshops in schools;

- collaborative projects where researchers and the public work together to gather data and inform policy; and

- the use of the Internet in the form of social media platforms such as (science) blogs, Facebook and Twitter, among others [e.g. RCUK, 2010]. 
New media platforms, and in particular social media, open up new avenues for public engagement, including dialogue between scientists and non-scientists without the involvement of journalists or other mediators [Dudo, 2013; Liang et al., 2014; Peters et al., 2014]. For the purpose of this study, we defined public science communication broadly, including the mediated, face-to-face and online interactions between scientists and society listed above.

\section{The rationale for public communication of science}

The notion that publicly funded scientists share a responsibility to communicate to non-specialist publics and engage them about their research is now widely accepted, not only by research funders and managers, but also by scientists themselves [Corley, Kim and Scheufele, 2011; Grand et al., 2015; Kyvik, 2005]. Some scholars argue that scientists have a moral duty to communicate with non-specialist audiences, especially when their work have implications for the broad society [European Commission, 2007; Marcinkowski et al., 2014; Torres-Albero et al., 2011].

Communicating scientific advances to broad public and policy audiences is increasingly recognised as a central requirement for influence and leadership, as well as a societal obligation and even as essential for the survival of science [Baron, 2010; Gieryn, 1983; Greenwood and Riordan, 2001; Parsons, 2001; Smith et al., 2013; Wright, 2015]. Research funders encourage scientists to engage in order to achieve broad societal impact [Nadkarni and Stasch, 2013; Neresini and Bucchi, 2011; Skrip, 2015]. In terms of scientists' own engagement objectives, Dudo and Besley [2016] found that they care most about combating misinformation and educating the public.

Research into the communication behaviour of scientists
Over the last two decades (1997-2016), a considerable quantity of research has been produced that explored and analysed the influence of a range of factors on scientists' involvement in public engagement. These studies are very diverse in terms of research objectives, sample populations and research methodologies. The common theme is that all of these studies sought to clarify the factors - enabling or constraining - that influence scientists' involvement in public science engagement.

Some researchers have focused on mediated communication, exploring the inherent challenges and benefits that emerge when scientists interact with journalists [Dunwoody, Brossard and Dudo, 2009; Peters, 2013]. Others have explored the barriers and incentives that are relevant when scientists interact directly with the public, for example at science fairs, science cafés and open-door events [Martín-Sempere, Garzón-García and Rey-Rocha, 2008; Mizumachi et al., 2011]. Some studies focused specifically on engagement in particular fields, for example nanoscientists [Dudo et al., 2014] or neuroscientists [Koh et al., 2016]. Researchers have also explored the effect of biographical factors, such as gender, discipline and career stage, on scientists' engagement behaviour [Besley, Oh and Nisbet, 2013; BBSRC, 2014; Crettaz von Roten, 2011; Ecklund, James and Lincoln, 2012; Johnson, Ecklund and Lincoln, 2014].

Some large-scale surveys of thousands of scientists within and across countries have investigated the broad spectrum of ways by which scientists communicate 
and engage, ranging from talks at schools and working with science centres to using cutting-edge social media tools [Pew Research Center, 2009; The Royal Society, 2006; TNS BMRB, 2015].

Another angle for exploring the engagement behaviour of scientists has been to focus on the reasons why they engage [Besley et al., 2016; Dunwoody, Brossard and Dudo, 2009; Poliakoff and Webb, 2007; Tsfati, Cohen and Gunther, 2011] or to look at the influence of the institutions where the scientists work [Crettaz von Roten and Goastellec, 2015; Jacobson, Butterill and Goering, 2004; Marcinkowski et al., 2014].

The rise of new media has created a multitude of new communication and engagement channels and platforms for scientists, leading understandably to a number of recent studies, which focused on how and why scientists engage their publics online [Liang et al., 2014; Lo and Peters, 2016].

\section{Regional differences}

Given that the current study was done in Africa, studies focusing on regional differences in scientists' involvement were of particular interest. Comparative studies of the public engagement practices of scientists in the East (Taiwan and China) and the West (Germany, the United States and the United Kingdom), Lo and Peters [2015], Lo and Peters [2016], Lo [2016] and Ren et al. [2014] report that scientists in the East were generally less involved in public science engagement and attached a lower value to these activities, compared to scientists in the West. Despite the strong differences in research practices in so-called 'central' and 'peripheral' countries, Kreimer, Levin and Jensen [2011] found that patterns of science popularisation in Argentina did not differ substantially from those in France and the United Kingdom.

\section{Barriers to public communication and engagement}

Andrews et al. [2005] found that scientists at all career stages face similar barriers to participating in outreach, namely logistics, time constraints and low status as well as the lack of skills and recognition. Furthermore, many scientists do not regard public communication as legitimate work that will be recognised or rewarded, but rather as a form of volunteer work [Andrews et al., 2005]. Some even regard it as a potentially harmful activity that could hurt their career prospects, and consequently, they may be reluctant to get involved [Gascoigne and Metcalfe, 1997] and worried about venturing into unfamiliar social spaces [Burchell, Franklin and Holden, 2009]. Scientists are concerned about negative reactions from their peers and colleagues, a lack of training opportunities and the expectation that they may have to adapt their work habits to reach public audiences whom they do not know well [Agnella et al., 2012; Lévy-Leblond, 1992; Martín-Sempere, Garzón-García and Rey-Rocha, 2008; Miller, 1998].

Bentley and Kyvik [2011] found that relatively few scientists publish popular science articles. The authors suggest that time pressures, a lack of incentives and a lack of access to relevant public communication channels could explain why scientists prioritise scientific publishing over popular science writing. Interestingly, the authors found that those scientists who are active popularisers, also have 
higher levels of scientific publishing and academic rank. The positive link between scientific productivity and public engagement was confirmed by Jensen [2011] and Wigren-Kristoferson, Gabrielsson and Kitagawa [2011].

Scientists' views of the public may also influence how they feel about communicating with the public. Several studies confirm that most scientists believe that the public simply do not know enough about science, and that they are largely not interested [Besley and Nisbet, 2011; Burchell, 2007; Ipsos MORI, 2001;

Vetenskap and Allmänhet, 2003; Young and Matthews, 2007]. This reflects the so-called 'deficit model' of science communication [Brossard and Lewenstein, 2010], which views low levels of scientific illiteracy as the root of public opposition towards emerging technologies and other science-based issues that should be remedied by providing the public with as much information as possible [Davies, 2008]. Recent thinking in public science communication has shifted away from one-way transmission of information towards dialogue and participatory practice aimed at involving the public in dialogue, participation and even co-creation of new knowledge [Holliman et al., 2015; Stocklmayer, 2001; van der Sanden and Meijman, 2008].

\section{Institutional support (or lack thereof) for public science communication}

Scientists are not isolated when they do research, nor when they interact with the public. Instead, their behaviour and performance are influenced by the motivations and resources, including the public relations (PR) policies and staff coming from the organisations where they are employed [Casini and Neresini, 2013; Entradas and Bauer, 2016]. Several studies have shown that organisational culture, strategies and policies are key factors in determining scientists' involvement in public science communication [Entradas and Bauer, 2016; France, Cridge and Fogg-Rogers, 2015; Horst, 2013; Jacobson, Butterill and Goering, 2004; Marcinkowski et al., 2014].

A lack of institutional support — and specifically a lack of resources and managerial support - is a commonly cited barrier in scientists' public communication activities, and several studies confirm that a lack of financial, social or career (promotion) rewards deter academic staff from getting involved in public communication [Bentley and Kyvik, 2011; Dudo, 2013; Searle, 2013; Torres-Albero et al., 2011]. Searle [2011] found that, if communication with the public was not formally part of their job description or written into the duty statement or project requirement, scientists were not likely to communicate. Casini and Neresini [2013] confirm that failure on the part of research organisations to recognise societal engagement as a legitimate part of the research profession hampers public engagement. Marcinkowski et al. [2014] provide evidence of how a university's desire for media visibility influences scientists' own media efforts.

According to the Concordat for engaging the public with research in the United Kingdom [RCUK, 2010], public engagement should be embedded within the mission statement, key strategies and operational plans of research organisations. Top management needs to support such a strategy for the organisation's public engagement, and this needs to be communicated effectively to staff and external stakeholders. The Royal Society [2006] found that leadership support would encourage young scientists to participate in public communication while, in the 
absence of university support and guidance, academics were unlikely to prioritise public engagement, and their efforts remain sporadic and uncoordinated.

Silva and Bultitude [2009] further state that effective training in public communication skills could enhance successful public engagement, but more needs to be done to develop and implement effective training. Besley et al. [2016] call for a more strategic, goal-oriented approach to science communication training, instead of the prevailing emphasis on skills development.

While most scientists welcome communication incentives and support from funders and employers, some are concerned about the lack of autonomy that becomes implicit when institutional policies demand involvement [Burchell, Franklin and Holden, 2009; Davies, 2013; Ipsos MORI, 2001].

\section{Most scientists do (and want to) engage}

Despite sub-ideal conditions and a lack of academic prestige and financial incentives, several studies - including some large-scale, national surveys - report that researchers are generally committed to engagement with their communities both in principle and practice [Bond and Paterson, 2005; Dang and Russo, 2015; Pew Research Center, 2009; Sturzenegger-Varvayanis et al., 2008; The Royal Society, 2006; TNS BMRB, 2015]. These studies show that the vast majority of researchers believe that:

- public engagement is important;

- they accept such engagement as a responsibility;

- they are involved in a wide range of activities; and

- most of them are keen to invest more time and resources into interacting with society.

\section{Motivators and benefits}

Some scientists are motivated towards public engagement by a sense of duty, but also to recruit students and secure funding [Bond and Paterson, 2005; Casini and Neresini, 2013], while others are driven by institutional demands [Whitmer et al., 2010]. Scientists also find intrinsic reward in the self-reflection that comes with public engagement, as well as personal satisfaction from engaging with the public [Holland, 1999; Watermeyer, 2015].

\section{Conflicting demands, but times are changing}

Burchell, Franklin and Holden [2009] highlight an anomaly in the emerging field of public science engagement. One the one hand, engagement with the public is increasingly acknowledged as an important aspect of the scientific profession. Yet, at the same time - and in contrast to other core scientific activities - engagement is generally viewed as "under-incentivised and under-rewarded, potentially 
detrimental to research, and professionally stigmatising" (p. 7). Davies [2013] agrees that there is a central tension in the drive towards public engagement in the U.K. academic environment - advocated and demanded on the one hand, but challenging to practice on the other.

However, a positive shift towards endorsement and recognition of public engagement within the culture of science is noted by Burchell, Franklin and Holden [2009], who point out that scientists reflect on public engagement in a "more sophisticated, layered and nuanced way than before" (p. 6) and that they are becoming increasingly confident and enthusiastic about public engagement.

Research question Against the background of the findings presented by the literature survey, the current study explored the public science communication views and practices of African scientists, focusing on academics at the NUST in Zimbabwe. Our key research question was: What is the status of public science communication at NUST, as indicated by the science communication views, strategies and practices of selected academics? To answer this question, the study explored how NUST academics communicate their research within and beyond academia, as well as their priority audiences, platforms and timing of communication.

Methodology

The methodology involved a survey of NUST academics, followed by interviews with selected participants.

The grouping of academic staff members who participated in the survey was as follows: professors, associate professors, senior lecturers, lecturers, research fellows, staff development fellows and teaching assistants. ${ }^{1}$

At the time of the study (October to December 2014), NUST recorded 413 academic staff members across its seven faculties. Of these, 94 were on study leave at the time and did not participate in the study. A further 19 academics declined to participate. In total, 113 of the 413 academics were not available, meaning that we could hand the printed questionnaires to only 300 academics. Of these, 198 academics completed and returned the questionnaire - a $66 \%$ response rate - of which $68 \%$ were men and $32 \%$ women. Only $7 \%$ of respondents were at a senior level (professor, associate professor or senior lecturer), which closely matched the representation of these three groups amongst the NUST population of academics. Table 1 provides detail on the distribution and response rates per faculty. The highest response rate was associated with the Faculty of Industrial Technology

\footnotetext{
${ }^{1} \mathrm{~A}$ research fellow is an academic research position for academic staff with a master's degree. Research fellow duties comprise conducting research in faculties, and attracting research grant funding to the faculties and to the university at large. A staff development fellow is appointed by the university in order to pursue a programme of studies as laid down by the university with a view to being appointed to the university staff after completion of studies. Apart from undertaking studies, staff development fellows are required to engage in academic research work and in any other research projects being undertaken by the departments within which they are engaged. Teaching assistants are employed on two-year contracts, and their duties comprise conducting tutorials, research and community service. The terms and conditions of their employment are such that as soon as they are engaged by the university, they are required to enrol in a master's programme for a two-year duration. As part of their studies they are supposed to undertake a research project [Parliament of Zimbabwe, 1990].
} 
$(80 \%)$ and the lowest with the Faculty of Applied Sciences (58\%). For analytical purposes, the seven faculties were also grouped into three 'science cultures' (Engineering and the Built Environment [EBE], Natural Sciences and Medicine $[\mathrm{NSM}]$ and Social and Economic Sciences [SES]). The respective science cultures are indicated in brackets in the first column in Table 1.

Table 1. Questionnaire distribution per faculty.

\begin{tabular}{|c|c|c|c|c|c|c|c|c|}
\hline \multirow[t]{2}{*}{ Faculty } & \multicolumn{2}{|c|}{$\begin{array}{c}\text { Total number } \\
\text { of academic } \\
\text { staff at NUST } \\
\text { [a] }\end{array}$} & \multicolumn{2}{|c|}{$\begin{array}{c}\text { Number of } \\
\text { questionnaires } \\
\text { distributed } \\
{[b]}\end{array}$} & \multicolumn{2}{|c|}{$\begin{array}{l}\text { Number of } \\
\text { questionnaires } \\
\text { returned } \\
\text { [c] }\end{array}$} & \multicolumn{2}{|c|}{$\begin{array}{c}\%) \\
\text { Response } \\
\text { rate }\end{array}$} \\
\hline & Count & $\%$ & Count & $\%$ & Count & $\%$ & & \\
\hline $\begin{array}{l}\text { Applied Sciences } \\
\text { (NSM) }\end{array}$ & 122 & $30 \%$ & 95 & $32 \%$ & 55 & $28 \%$ & $45 \%$ & $58 \%$ \\
\hline Commerce (SES) & 117 & $28 \%$ & 83 & $28 \%$ & 57 & $29 \%$ & $49 \%$ & $69 \%$ \\
\hline $\begin{array}{l}\text { Communication } \\
\text { and Information } \\
\text { Science (SES) }\end{array}$ & 51 & $12 \%$ & 40 & $13 \%$ & 27 & $14 \%$ & $53 \%$ & $68 \%$ \\
\hline $\begin{array}{l}\text { Industrial } \\
\text { Technology (EBE) }\end{array}$ & 46 & $11 \%$ & 30 & $10 \%$ & 24 & $12 \%$ & $52 \%$ & $80 \%$ \\
\hline $\begin{array}{l}\text { Built } \\
\text { Environment } \\
\text { (EBE) }\end{array}$ & 26 & $6 \%$ & 19 & $6 \%$ & 12 & $6 \%$ & $46 \%$ & $63 \%$ \\
\hline Medicine (NSM) & 40 & $10 \%$ & 25 & $8 \%$ & 18 & $9 \%$ & $45 \%$ & $72 \%$ \\
\hline $\begin{array}{l}\text { Science and } \\
\text { Technology } \\
\text { Education (SES) }\end{array}$ & 11 & $3 \%$ & 8 & $3 \%$ & 5 & $2 \%$ & $45 \%$ & $63 \%$ \\
\hline Total & 413 & $100 \%$ & 300 & $100 \%$ & 198 & $100 \%$ & $48 \%$ & $66 \%$ \\
\hline
\end{tabular}

EBE $=$ Engineering and the Built Environment; NSM = Natural Sciences and Medicine; $\mathrm{SES}=$ Social and Economic Sciences

Quantitative questionnaire
The questionnaire for the survey enquired about the research activities of academics and the strategies used by academics in public science communication, as well as the communication support and training provided by NUST. We formulated our questions guided by earlier studies done by Kyvik [2005], Suleski and Ibaraki [2010], Bentley and Kyvik [2011], Besley and Tanner [2011], Searle [2011], Torres-Albero et al. [2011], Tsfati, Cohen and Gunther [2011] and Dudo [2013].

The questionnaire had seven sections (A-G). Section A focused on the proportion of researchers who were active in dissemination, and on the research productivity of these academics. Section $C$ focused on university policies for science communication, and section D explored the views of academics on institutions' recognition of science communication activities. The formulation of questions for sections A, C and D was guided by a study done by Jensen et al. [2008].

The formulation of section B, which focused on academics' public communication strategies, was guided by research done by Searle [2011]. Section E sought to establish whether participating researchers engaged with journalists, while section $\mathrm{F}$ examined the nature of the interaction between scientists and the media. Section $\mathrm{G}$ enquired about the status of science communication training at NUST. 
The questionnaire, which was pre-tested on 20 academics, comprised mainly closed questions, but a few open-ended questions allowed respondents to elaborate on specific topics. NUST provided ethical clearance and approval for the study. All study participants gave their informed consent.

Qualitative interviews

\section{Results}

Awareness and understanding of the term "science communication"
An interview guide - based on the objectives of the study - directed the process of interviewing respondents. (See Appendix A for a copy of the interview guide.) Semi-structured interviews were conducted with five research-active ${ }^{2}$ staff in each of the faculties, i.e. 35 academics in total. Interviews were done at the level of professor, lecturer and research fellow because these categories were involved in more research than the lower categories of teaching assistant and staff development fellow. Interview questions for the respondents were derived from the objectives of the study. Respondents were asked about their views on public science engagement, sharing science via the mass media, and the value of communication training workshops. Respondents were further asked about the challenges they face when trying to engage in public science communication activities. Since many interviewees did not agree to audio recording of the interviews, their answers were captured by taking notes. Our analysis consisted of sorting the data according to the rank of the respondents, followed by identifying, coding and categorising emerging patterns and themes.

As background to gathering information on the science communication views and practices of NUST academics, this study determined whether all respondents were actively involved in research and how they understood the term "science communication".

Altogether, $72 \%$ of the 198 respondents stated that, at the time of the survey, they were actively involved in research, while $93 \%$ had been research-active in the preceding five years. The 35 interviewees were selected based on their involvement in research at the time of the research. Chi-square tests revealed no statistically significant differences between science cultures or faculties at the time of the survey (Table 2).

No statistically significant differences based on chi-square tests:

$$
\begin{aligned}
& \text { - science culture }-\chi^{2}(2, N=198)=1.34, \mathrm{p}=0.51 \\
& \text { - faculty }-\chi^{2}(6, N=198)=4.78, \mathrm{p}=0.57
\end{aligned}
$$

In response to a question about the term "science communication", $50 \%$ of the respondents said that they were aware of this term, 14\% were unsure, and 36\% were not aware of the existence of the term.

Two themes emerged from the definitions for science communication provided by the survey respondents (and also interview participants). Some presented a

\footnotetext{
${ }^{2}$ The Director of the Research and Innovation Office (RIO) confirmed that academics were considered to be research-active (the selection criterion) if they had submitted at least five applications for research funding to the RIO at NUST between 2010 and 2014.
} 
Table 2. Cross-tabulation of science culture and faculty with research involvement at the time of the survey.

\begin{tabular}{|c|c|c|c|c|c|}
\hline \multirow[t]{2}{*}{$\begin{array}{l}\text { Science } \\
\text { cultures }\end{array}$} & \multicolumn{2}{|c|}{$\begin{array}{c}\text { Involved in } \\
\text { research at } \\
\text { time of survey }\end{array}$} & \multirow[t]{2}{*}{ Faculties } & \multicolumn{2}{|c|}{$\begin{array}{c}\text { Involved in } \\
\text { research at } \\
\text { time of survey }\end{array}$} \\
\hline & Yes & No & & Yes & No \\
\hline \multirow{2}{*}{$\begin{array}{l}\mathrm{EBE} \\
(\mathrm{N}=36)\end{array}$} & \multirow{2}{*}{$72 \%$} & \multirow{2}{*}{$28 \%$} & Built Environment $(\mathrm{N}=12)$ & $58 \%$ & $42 \%$ \\
\hline & & & Industrial Technology $(\mathrm{N}=24)$ & $79 \%$ & $21 \%$ \\
\hline \multirow{2}{*}{$\begin{array}{l}\text { NSM } \\
(\mathrm{N}=73)\end{array}$} & \multirow{2}{*}{$77 \%$} & \multirow{2}{*}{$23 \%$} & Applied Sciences $(\mathrm{N}=55)$ & $76 \%$ & $24 \%$ \\
\hline & & & Medicine $(\mathrm{N}=18)$ & $78 \%$ & $22 \%$ \\
\hline \multirow{3}{*}{$\begin{array}{l}\text { SES } \\
(\mathrm{N}=89)\end{array}$} & \multirow{3}{*}{$69 \%$} & \multirow{3}{*}{$31 \%$} & Commerce $(\mathrm{N}=57)$ & $65 \%$ & $35 \%$ \\
\hline & & & Communication and Information Science $(\mathrm{N}=27)$ & $78 \%$ & $22 \%$ \\
\hline & & & Science and Technology Education $(\mathrm{N}=5)$ & $60 \%$ & $40 \%$ \\
\hline
\end{tabular}

$\mathrm{EBE}=$ Engineering and the Built Environment; NSM = Natural Sciences and Medicine; SES $=$ Social and Economic Sciences

'traditional interpretation' confined to communication within academia (i.e. sharing findings via scientific articles and conferences), while others included 'broader audiences' and the idea of communicating research findings outside the scientific community. Those who used the 'traditional interpretation', described the term as denoting "sharing one's findings in a conference", "communicating to peers in the field", and "getting my research published". Those who captured broader audiences, described the term as "reaching out" or "speaking out about my findings" to society, while some mentioned "the media" as a key audience.

Public science communication at NUST: audiences, platforms and timing
The respondents were given a list of audiences and had to select those with whom they usually communicate about their research findings. Figure 1 shows that participating NUST academics mainly communicate to fellow academics (68\%) and to students $(64 \%)$, with markedly fewer communicating to the general public $(28 \%)$ and policy makers (19\%). Only $11 \%$ indicated that they targeted the mass media as an audience for their research findings.

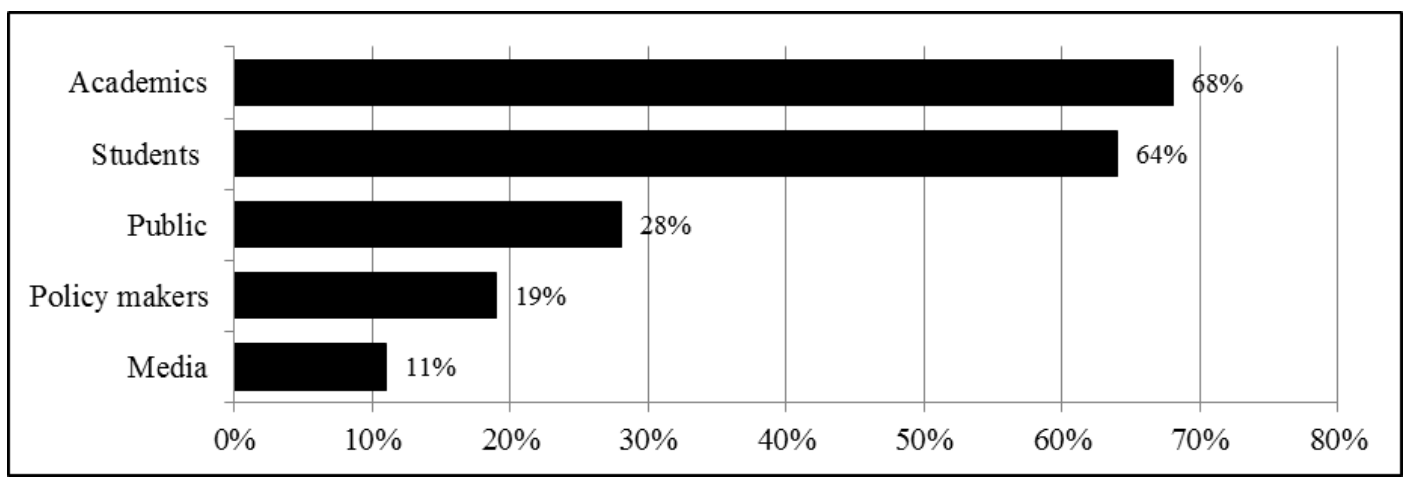

Figure 1. Audiences targeted in public science communication activities $(\mathrm{N}=188)$.

The communication of research to external audiences (i.e. to the public, policy makers and the media, respectively) was cross-tabulated with faculty membership and science culture (Table 3). None of these cross-tabulations turned out to be statistically significant, although some marked differences were observed in terms of faculties. For instance, compared to other faculties, respondents from the Faculty 
of Medicine were less likely to have communicated the findings of their research to any of the three external audiences.

Table 3. Cross-tabulation of science culture and faculty with communication of research to three kinds of external audiences (public, policy makers and the media).

\begin{tabular}{|c|c|c|c|c|c|}
\hline \multirow[t]{2}{*}{$\begin{array}{l}\text { Science } \\
\text { cultures }\end{array}$} & \multicolumn{2}{|c|}{$\begin{array}{l}\text { Communication } \\
\text { to the public }\end{array}$} & \multirow[t]{2}{*}{ Faculties } & \multicolumn{2}{|c|}{$\begin{array}{l}\text { Communication } \\
\text { to the public }\end{array}$} \\
\hline & Yes & No & & Yes & No \\
\hline \multirow{2}{*}{$\begin{array}{l}\text { EBE } \\
(\mathrm{N}=36)\end{array}$} & \multirow{2}{*}{$33 \%$} & \multirow{2}{*}{$67 \%$} & Built Environment $(\mathrm{N}=12)$ & $33 \%$ & $67 \%$ \\
\hline & & & Industrial Technology $(\mathrm{N}=24)$ & $33 \%$ & $67 \%$ \\
\hline \multirow{2}{*}{$\begin{array}{l}\text { NSM } \\
(\mathrm{N}=69)\end{array}$} & \multirow{2}{*}{$26 \%$} & \multirow{2}{*}{$74 \%$} & Applied Sciences $(\mathrm{N}=53)$ & $30 \%$ & $70 \%$ \\
\hline & & & Medicine $(\mathrm{N}=16)$ & $13 \%$ & $88 \%$ \\
\hline \multirow{3}{*}{$\begin{array}{l}\text { SES } \\
(\mathrm{N}=83)\end{array}$} & \multirow{3}{*}{$27 \%$} & \multirow{3}{*}{$73 \%$} & Commerce $(\mathrm{N}=55)$ & $27 \%$ & $73 \%$ \\
\hline & & & Communication and Information Science $(\mathrm{N}=23)$ & $26 \%$ & $74 \%$ \\
\hline & & & Science and Technology Education $(\mathrm{N}=5)$ & $20 \%$ & $80 \%$ \\
\hline \multirow[t]{2}{*}{$\begin{array}{l}\text { Science } \\
\text { cultures }\end{array}$} & \multicolumn{2}{|c|}{$\begin{array}{l}\text { Communication } \\
\text { to policy makers }\end{array}$} & \multirow[t]{2}{*}{ Faculties } & \multicolumn{2}{|c|}{$\begin{array}{l}\text { Communication } \\
\text { to policy makers }\end{array}$} \\
\hline & Yes & No & & Yes & No \\
\hline \multirow{2}{*}{$\begin{array}{l}\text { EBE } \\
(N=36)\end{array}$} & \multirow{2}{*}{$22 \%$} & \multirow{2}{*}{$78 \%$} & Built Environment $(\mathrm{N}=12)$ & $33 \%$ & $67 \%$ \\
\hline & & & Industrial Technology $(\mathrm{N}=24)$ & $17 \%$ & $83 \%$ \\
\hline \multirow{2}{*}{$\begin{array}{l}\text { NSM } \\
(\mathrm{N}=69)\end{array}$} & \multirow{2}{*}{$16 \%$} & \multirow{2}{*}{$84 \%$} & Applied Sciences $(\mathrm{N}=53)$ & $21 \%$ & $79 \%$ \\
\hline & & & Medicine $(\mathrm{N}=16)$ & $0 \%$ & $100 \%$ \\
\hline \multirow{3}{*}{$\begin{array}{l}\text { SES } \\
(\mathrm{N}=83)\end{array}$} & \multirow{3}{*}{$19 \%$} & \multirow{3}{*}{$81 \%$} & Commerce $(\mathrm{N}=55)$ & $18 \%$ & $82 \%$ \\
\hline & & & Communication and Information Science (N=23) & $17 \%$ & $83 \%$ \\
\hline & & & Science and Technology Education (N=5) & $40 \%$ & $60 \%$ \\
\hline \multirow[t]{2}{*}{$\begin{array}{l}\text { Science } \\
\text { cultures }\end{array}$} & \multicolumn{2}{|c|}{$\begin{array}{l}\text { Communication } \\
\text { to the media }\end{array}$} & \multirow[t]{2}{*}{ Faculties } & \multicolumn{2}{|c|}{$\begin{array}{l}\text { Communication } \\
\text { to the media }\end{array}$} \\
\hline & Yes & No & & Yes & No \\
\hline \multirow{2}{*}{$\begin{array}{l}\text { EBE } \\
(N=36)\end{array}$} & \multirow{2}{*}{$11 \%$} & \multirow{2}{*}{$89 \%$} & Built Environment $(\mathrm{N}=12)$ & $8 \%$ & $92 \%$ \\
\hline & & & Industrial Technology $(\mathrm{N}=24)$ & $13 \%$ & $87 \%$ \\
\hline NSM & $7 \%$ & $93 \%$ & Applied Sciences $(\mathrm{N}=53)$ & $9 \%$ & $91 \%$ \\
\hline$(\mathrm{N}=69)$ & $1 \%$ & $93 \%$ & Medicine $(\mathrm{N}=16)$ & $0 \%$ & $100 \%$ \\
\hline SES & & & Commerce $(\mathrm{N}=55)$ & $13 \%$ & $87 \%$ \\
\hline$(\mathrm{N}=83)$ & $13 \%$ & $87 \%$ & Communication and Information Science (N=23) & $17 \%$ & $83 \%$ \\
\hline & & & Science and Technology Education $(\mathrm{N}=5)$ & $0 \%$ & $100 \%$ \\
\hline
\end{tabular}

$\mathrm{EBE}=$ Engineering and the Built Environment; NSM = Natural Sciences and Medicine; SES $=$ Social and Economic Sciences

No statistically significant differences based on chi-square tests:

- public [science culture $-\chi^{2}(2, N=188)=0.72, \mathrm{p}=0.70$; faculty $\left.\chi^{2}(6, N=188)=2.77, \mathrm{p}=0.84\right]$

- policy makers [science culture $-\chi^{2}(2, N=188)=0.66, \mathrm{p}=0.72$; faculty $\left.\chi^{2}(6, N=188)=7.13, \mathrm{p}=0.31\right]$

- the media [science culture $-\chi^{2}(2, N=188)=1.44, \mathrm{p}=0.49$; faculty $\left.\chi^{2}(6, N=188)=4.10, \mathrm{p}=0.66\right]$

The study also sought to determine the platforms that academics at NUST use for science communication. Figure 2 shows respondents' preferred channels for communicating their research findings. Multiple selections applied.

The majority of respondents preferred academic platforms for communication, such as conferences $(73 \%)$ and seminars $(69 \%)$. Only a small proportion used social media, mostly blogs (14\%). 


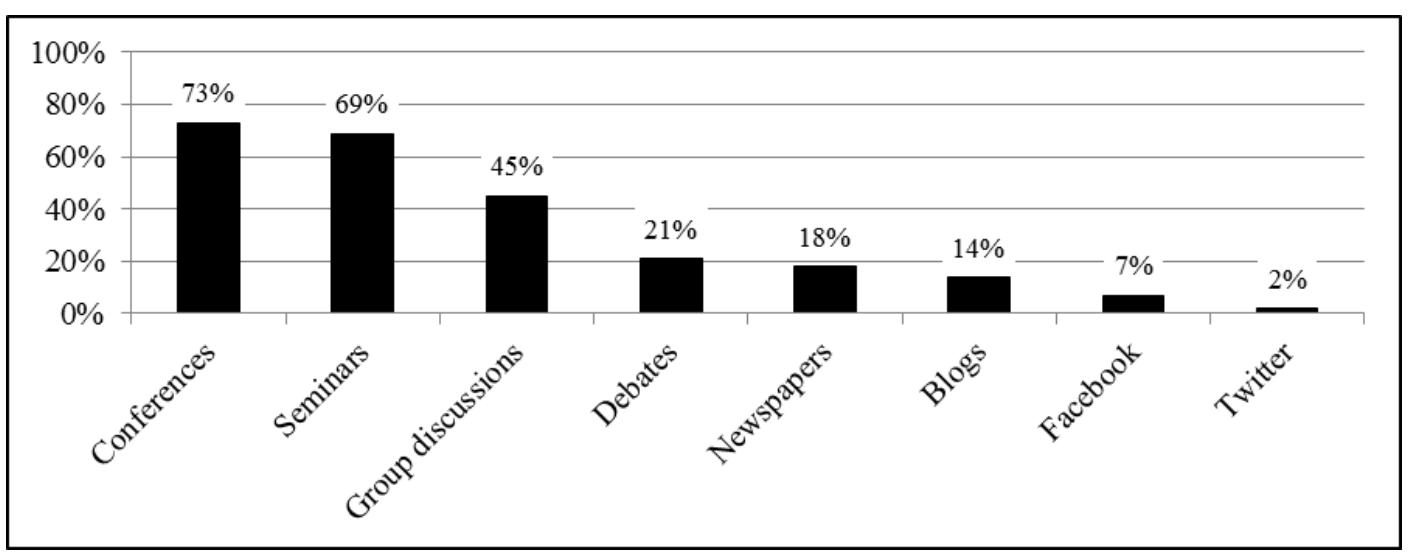

Figure 2. Science communication platforms directed at academic and non-academic audiences $(\mathrm{N}=163)$.

In response to a question that contrasted the preference for journal articles with public engagement, more than half (52\%) of respondents said that they would prefer to publish in journals without further engaging the public in their research work, while $48 \%$ of the survey respondents favoured both activities. No statistically significant differences were found for either science culture or faculty (Table 4).

Table 4. Cross-tabulation of science culture and faculty with question whether to publish in journals without further engaging the public.

\begin{tabular}{|c|c|c|c|c|c|}
\hline \multirow[t]{2}{*}{$\begin{array}{l}\text { Science } \\
\text { cultures }\end{array}$} & \multicolumn{2}{|c|}{$\begin{array}{l}\text { Answer to } \\
\text { question }\end{array}$} & \multirow[t]{2}{*}{ Faculties } & \multicolumn{2}{|c|}{$\begin{array}{l}\text { Answer to } \\
\text { question }\end{array}$} \\
\hline & Yes & No & & Yes & No \\
\hline \multirow{2}{*}{$\begin{array}{l}\text { EBE } \\
(\mathrm{N}=36)\end{array}$} & \multirow{2}{*}{$53 \%$} & \multirow{2}{*}{$47 \%$} & Built Environment $(\mathrm{N}=12)$ & $33 \%$ & $67 \%$ \\
\hline & & & Industrial Technology $(\mathrm{N}=24)$ & $63 \%$ & $37 \%$ \\
\hline \multirow{2}{*}{$\begin{array}{l}\text { NSM } \\
(\mathrm{N}=73)\end{array}$} & \multirow{2}{*}{$52 \%$} & \multirow{2}{*}{$48 \%$} & Applied Sciences $(\mathrm{N}=55)$ & $58 \%$ & $42 \%$ \\
\hline & & & Medicine $(\mathrm{N}=18)$ & $33 \%$ & $67 \%$ \\
\hline \multirow{3}{*}{$\begin{array}{l}\text { SES } \\
(\mathrm{N}=89)\end{array}$} & \multirow{3}{*}{$53 \%$} & \multirow{3}{*}{$47 \%$} & Commerce $(\mathrm{N}=57)$ & $53 \%$ & $47 \%$ \\
\hline & & & Communication and Information Science $(\mathrm{N}=27)$ & $48 \%$ & $52 \%$ \\
\hline & & & Science and Technology Education $(\mathrm{N}=5)$ & $80 \%$ & $20 \%$ \\
\hline
\end{tabular}

$\mathrm{EBE}=$ Engineering and the Built Environment; NSM = Natural Sciences and Medicine; SES $=$ Social and Economic Sciences

No statistically significant differences based on chi-square tests:

$$
\begin{aligned}
& \text { - science culture }-\chi^{2}(2, N=198)=0.01, \mathrm{p}=0.99 \\
& \text { - faculty }-\chi^{2}(6, N=198)=7.82, \mathrm{p}=0.25
\end{aligned}
$$

The survey also explored respondents' timing of communicating to public and policy audiences. Accordingly, $22 \%$ of respondents stated that they communicated their findings immediately after completion of the research, while $31 \%$ communicated their findings to public and policy audiences within five years. The majority $(47 \%)$ indicated that they did not share their findings with public and policy audiences. These percentages did not differ significantly for the three science cultures or seven faculties (Figure 3). 


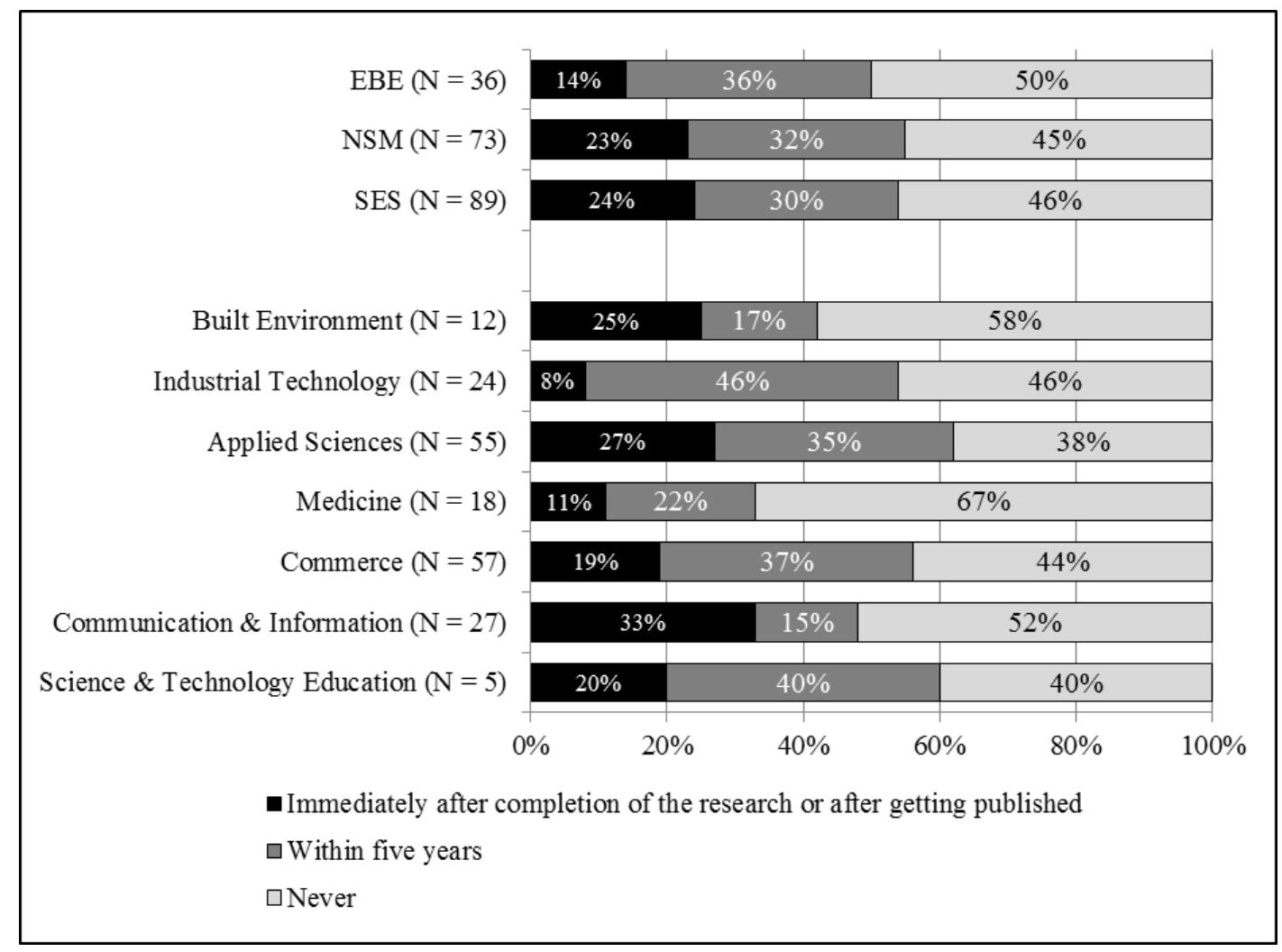

Figure 3. Cross-tabulation of science culture and faculty with question on timing of communicating to public and policy audiences.

No statistically significant differences based on chi-square tests:

- science culture $-\chi^{2}(4, N=198)=1.64, \mathrm{p}=0.80$

- faculty $-\chi^{2}(12, N=198)=14.65, \mathrm{p}=0.26$

Lastly, for research evidence to contribute to the development of society and to be meaningful to non-scientific audiences, scientific information must be communicated in a way that lay people can understand. Of the respondents, $79 \%$ were of the opinion that it would be difficult for them to explain scientific facts to journalists in a way that lay audiences could understand. Again, no statistically significant differences were found for either science culture or faculty (Table 5).

No statistically significant differences based on chi-square tests:

- science culture $-\chi^{2}(2, N=189)=0.34, \mathrm{p}=0.85$

- faculty $-\chi^{2}(6, N=189)=4.46, \mathrm{p}=0.62$

\section{Institutional support mechanisms and challenges}

Regarding the perceptions of academics on the availability or non-availability of a university science communication policy, most of the respondents $(65 \%)$ were not sure whether the university had a science communication policy, with some respondents stating that there was actually no policy. The Director of the Research 
Table 5. Cross-tabulation of science culture and faculty with how difficult it is to explain scientific facts to journalists in a way that lay people can understand.

\begin{tabular}{|c|c|c|c|c|c|}
\hline \multirow[t]{2}{*}{$\begin{array}{l}\text { Science } \\
\text { cultures }\end{array}$} & \multicolumn{2}{|c|}{$\begin{array}{l}\text { Answer to } \\
\text { question }\end{array}$} & \multirow[t]{2}{*}{ Faculties } & \multicolumn{2}{|c|}{$\begin{array}{c}\text { Answer to } \\
\text { question }\end{array}$} \\
\hline & Easy & Difficult & & Easy & Difficult \\
\hline \multirow{2}{*}{$\begin{array}{l}\text { EBE } \\
(\mathrm{N}=34)\end{array}$} & \multirow{2}{*}{$18 \%$} & \multirow{2}{*}{$82 \%$} & Built Environment $(\mathrm{N}=11)$ & $18 \%$ & $82 \%$ \\
\hline & & & Industrial Technology $(\mathrm{N}=23)$ & $17 \%$ & $83 \%$ \\
\hline \multirow{2}{*}{$\begin{array}{l}\text { NSM } \\
(\mathrm{N}=71)\end{array}$} & \multirow{2}{*}{$23 \%$} & \multirow{2}{*}{$77 \%$} & Applied Sciences $(\mathrm{N}=53)$ & $26 \%$ & $74 \%$ \\
\hline & & & Medicine $(\mathrm{N}=18)$ & $11 \%$ & $89 \%$ \\
\hline \multirow{3}{*}{$\begin{array}{l}\text { SES } \\
(\mathrm{N}=84)\end{array}$} & \multirow{3}{*}{$21 \%$} & \multirow{3}{*}{$79 \%$} & Commerce $(\mathrm{N}=55)$ & $26 \%$ & $74 \%$ \\
\hline & & & Communication and Information Science $(\mathrm{N}=24)$ & $17 \%$ & $83 \%$ \\
\hline & & & Science and Technology Education $(\mathrm{N}=5)$ & $0 \%$ & $100 \%$ \\
\hline
\end{tabular}

$\mathrm{EBE}=$ Engineering and the Built Environment; NSM = Natural Sciences and Medicine; SES $=$ Social and Economic Sciences

and Innovation Office (RIO) at NUST was interviewed to clarify survey data on the availability of a science communication policy at the university. The Director of RIO indicated that, at the time of the survey, there was no science communication policy at NUST, but that the university was busy updating its research policy to address issues of research uptake and science communication. The amended research policy would be cascaded down to academics via future workshops.

The majority $(70 \%)$ of academics surveyed in this study agreed that, even without a university science communication policy, the university did encourage academics to participate in public science communication. The NUST research policy (at the time of the research) stated that the university encouraged research that was relevant to the needs of communities locally, regionally and internationally, and that such research needed to be communicated to the relevant stakeholders.

Most respondents (68\%) were either not sure or did not know whether the university rewarded academics for public science communication. Interview respondents indicated that, at the time of the research, there were no institutional rewards for public science communication.

Interviewees generally thought that the university did not compel them to communicate their findings to public and policy audiences, and noted that the university research office was mainly concerned with publication output from academics for promotion criteria purposes. More than $80 \%$ of respondents did not know whether they needed approval from the university before communicating with public and policy audiences, or thought that there was no need to get approval.

Other challenges that affect academics' participation in public science communication emerged from the surveys and interviews. These are discussed in the following sections.

\section{Unstable research funding}

Several interviewees commented that NUST funded research poorly because the university was financially unstable. Limited and uncertain research funding would logically also affect efforts to communicate externally. 


\section{Political sensitivities}

Another barrier - mentioned by $25 \%$ of the interviewees - related to the politically sensitive nature of some research. Despite the potential importance of research findings to policy makers and its relevance to society at large, it would not be possible for researchers to share some findings freely in the public domain. For example, one of the interviewees said,

Findings that are deemed to create panic or result in chaos in the nation are censored, for example, findings on the increased effects of climate change and issues pertaining to land tenure lost to fragmentation during the land reform era in Zimbabwe may lead to the researcher being prosecuted for treason.

\section{Low public science literacy}

The perceived inability of the Zimbabwean public to understand scientific research was mentioned by $75 \%$ of surveyed academics. One lecturer said, "The public is usually not in a position to understand complicated scientific discoveries, and it is difficult to communicate hard sciences to the public", while a professor stated, "Not all research activities are for public consumption, for example, research on pathogenic microbes might be most relevant to those in the medical field, so why should I share such research with people who will not understand it?".

\section{Low status of public communication}

Nearly two thirds of respondents (65\%) regarded science communication as an optional and potentially futile activity, instead of as part of their work. A lecturer explained,

My duties as an academic at NUST are to teach, do research and conduct community service. The research work that I do is for my academic advancement through publications in accredited journals. I am not paid for the extra hours that I have to put in to reach out to a public that, in the first place, does not even understand the research that I would have conducted. It is a mere waste of time to do that.

A senior lecturer noted, "There is no established platform for science communication and scientific researchers do not feel the need to communicate to the public, so there's a self-imposed barrier."

\section{Time constraints}

A lack of time and heavy teaching workloads were cited by $80 \%$ of the respondents across the seven faculties as hindrances to public science communication. One lecturer said, "We are in a weird set-up where there is no time to disseminate to the publics out there", while another remarked,

Some of us in the engineering field are very busy with teaching. I don't see any communication going on. At times, we do workshops for engineers in Zimbabwe and at times, we are invited to present papers, but going to communities or the public, who has time for that? 
Our results revealed that most NUST academics see the value of developing public science communication skills and are keen to be trained. Only $26 \%$ of respondents had some formal training in science communication (with $74 \%$ indicating that they had never received any such training), but more than $80 \%$ were willing to undergo training. In response to a question whether training in science communication would be useful to their research and beneficial to the university, $80 \%$ agreed. The rest $(20 \%)$ expressed concern about the expertise of the trainers and the relevance of a single training course across a wide range of disciplines.

Discussion of findings
The purpose of this study was to contribute to the current understanding of science communication views and practices of academic researchers within an African (developing world) university setting - using the National University of Science and Technology (NUST) in Zimbabwe as a test case. The communication strategies, training needs and the factors that affect the willingness of academics to engage in public science communication were investigated.

We found that NUST academics prioritise scholarly communication and prefer academic journals and scientific conferences as communication platforms, without engaging the public in their research work. These results are consistent with the findings of Bentley and Kyvik [2011] that popular science publishing is undertaken by a minority of academic staff and to a far lesser extent than scientific publishing. This is also confirmed by Wilcox [2012], who states that science is almost entirely a monologue given to a very specific audience, and scientists pride themselves on publishing in top-tier journals but the problem is that these publications only communicate science to other scientists. At NUST, this could be attributed to a culture where publishing in peer-reviewed journals is rewarded and carries considerable prestige and power in terms of promotion criteria.

Our study showed that, at the time of this research and across all faculties, there was little communication with the public, media and policy makers. These findings differ from developed-world studies, which found that the vast majority of academics are actively involved in public communication [Agnella et al., 2012; Searle, 2011; The Royal Society, 2006], and that researchers from the humanities and social sciences are generally more involved than their colleagues in natural sciences [Bentley and Kyvik, 2011; Kyvik, 2005; TNS BMRB, 2015; University of Kassel, 2008].

Almost $80 \%$ of the survey respondents, across all faculties, found it difficult to explain scientific facts in a way that lay people would understand. Baram-Tsabari and Lewenstein [2013] showed that communicating science to the lay public demands specialised skills, and in particular the ability to use non-technical language and norms when discussing science beyond the scientific community.

In addition, close to half of the survey respondents (46\%) had never communicated their findings to public and policy audiences, and almost two-thirds of respondents $(65 \%)$ believed that science communication was an optional activity rather than an integral part of their work. Moreover, $80 \%$ cited a lack of time and heavy teaching workloads as challenges to public science communication. These findings mirror 
those of Searle [2011] who found that the hindrance most frequently cited by scientists was the lack of time to communicate with the general public. In their study, Mizumachi et al. [2011] found that scientists already had too much to do and therefore viewed non-research tasks as bothersome activities that fell outside the scope of their work.

Despite the absence of a university policy focused on science communication at the time of the study, $70 \%$ of the surveyed academics agreed that there was some support by the university in terms of encouraging academics to participate in public science communication. The NUST Research Policy [2013] states that the university encourages research that is relevant to the needs of communities locally, regionally and internationally, and that such research needs to be communicated to the relevant stakeholders. The Royal Society study [2006] found that leadership support is important for academics to engage in the public communication of science and such support would also encourage junior scientists to participate in public communication.

The question whether employers should consider direct rewards for researchers' public engagement activities, was added to the public engagement agenda more recently [Burchell, 2015]. However, several scholars have shown how a lack of rewards and incentives, the low status of knowledge transfer compared to academic outputs, and a lack of funding and support limit scientists' involvement in public communication [Dudo, 2013; Jacobson, Butterill and Goering, 2004; Searle, 2011]. Globally, very few institutions reward academic staff directly for publishing popular articles or for being interviewed on radio or television [Heleta, 2016]. In South Africa, for example, only scientific publication channels are incentivised [Heleta, 2016]. The country's Department of Higher Education and Training and individual research institutions reward their staff for publishing books, book chapters, monographs or articles in accredited, peer-reviewed journals [Heleta, 2016]. This is also reflective of the scenario at NUST and generally in the Zimbabwean university setting.

Most of the researchers interviewed (75\%) believed that there was a lack of understanding by the public of scientific research work. The findings of the current study are comparable with those of a survey by the Pew Research Center for the People and the Press [2009, p. 2], which found that "the majority of scientists consider the public's lack of scientific knowledge to be a major problem for science". Horst [2013, p. 760] points out that several scholars have noted, "a deficit model of one-way communication is prevalent among scientists". The findings of the current study indicate that, at the time of the research, most academics at NUST were still in an era of one-way communication to a presumably illiterate public. However, current trends favour promoting dialogue in science communication. For example, Besley and Tanner [2011] suggest the contextual approach — giving a place for lay people in debates about scientific issues - as an alternative to the deficit model approach.

Appropriate training could help academics to overcome some of the barriers to dialogue. Most researchers do not know how to communicate with the public and do not understand their audience well enough [Treise and Weigold, 2002]. Besley and Tanner [2011] state that science communication training is very important for scientists in academic institutions as it guides them in public science 
communication activities. However, the majority of academics interviewed (74\%) indicated that they had never received any training in public science communication. Most were, however, willing to undergo training, and $80 \%$ agreed that training in public science communication would be useful to their own research and to the university.

In addition to the challenges listed above, public science engagement at NUST is further complicated by an unstable research funding environment and the perceived censorship of politically sensitive research findings.

Insight into academics' public science communication views and practices is crucial since it provides an understanding of how academics feel about and respond to growing demands to communicate to and engage with public audiences. The results of the current study revealed that most of the academics at NUST in Zimbabwe were not reaching out to the public and policy makers. Such behaviour was attributed to:

- a prevalence of the deficit model view of science communication;

- difficulty in making their findings more appealing for public consumption;

- lack of incentives to share their work with the public and policy audiences;

- low priority attached to public communication;

- a focus on publishing in academic journals; and

- a lack of time to reach out to public audiences.

The perceived instability of research funding at NUST and potential political sensitivities around certain research findings may further constrain academics' involvement in public engagement.

Clearly, a new mind-set amongst university academics and management is needed in order to make research done at African universities more accessible to public and policy audiences, and to clarify the benefits that scientific research offers to society.

While publishing in peer-reviewed journals is and will remain important, incentives and support are also required to recognise, reward and encourage public science engagement. Correspondingly, we recommend:

- Leadership (top management) at African universities should recognise, support and embrace public communication of science as a core duty of academic staff.

- University research offices should develop enabling/encouraging science communication policies to guide and support staff members in engaging public and policy audiences. 
- University science communication policy should be operationalised alongside promotional requirements, with expectations regarding public science communication clearly articulated in the work contracts of academics.

- Regular training programmes - designed to equip researchers with skills and confidence in making their research accessible to public audiences should be presented by science communication professionals.

- Researchers who excel at public science communication and engagement should be able to qualify and compete for some form of reward or prize.

- Academics should endeavour to include public communication alongside academic publishing, for example by using a peer-reviewed article as the basis for a popular article or press release, and by providing easily accessible popular summaries of peer-reviewed articles.

- Planning (and funding applications) for new research projects should include planning and budgeting for public communication and engagement.

- Academics should explore external funding sources to initiate and sustain public science communication and engagement activities.

Funding acknowledgement

Appendix A. Interview guide
This research was funded with support from the Development Research Uptake in Sub-Saharan Africa (DRUSSA) programme. The DRUSSA programme is funded by the Department for International Development (DfID), which is a United Kingdom government department responsible for administering overseas aid.

\section{Interpretation of the concept of science communication}

1. Are you aware of the concept of science communication? (Yes/No/Not sure)

2. If yes, how would you define public science communication in your own words?

3. Have you ever communicated your research findings to the following audiences? (Media/Lay public/Policy makers/Industry and commerce/Communities where research was conducted)

4. If you answered 'yes' to any of the above options, which channels do you use to reach out to the public and policy audiences?

5. Do you think the time that scientists spend (or that you spend) on communicating your work via the mass media is time well spent? (Yes/No/Not sure)

6. If no, what are the reasons? 


\section{Support mechanisms for science communication}

7. Do you think it is important to have a science communication policy for researchers at your university? (Yes/No/Not sure)

8. Give reasons for your response above.

9. Do you believe that research is adequately funded at NUST?

10. Give reasons for you answer above.

11. Do you believe that the university has a role to encourage academics to communicate their research findings to the relevant stakeholders in society? (Yes/No/Not sure)

12. Does the university incentivise public science communication (in the form of rewards or as part of promotional criteria)?

\section{Interaction between academics and the media}

13. Have you ever approached journalists as a channel to communicate your research findings through the media? (Yes/No/Not sure)

14. If yes, how have your experiences been with journalists in the past, in terms of communicating your research results through the media?

(Positive/Negative/Neutral)

15. If you answered 'no' to Question 13 above, what other channels do you use to reach out to the public and policy audiences?

16. Do you believe that journalists understand the research findings presented to them by scientists? (Yes/No/Not sure)

17. What other barriers do you think affect academics as they try to reach out to the public and policy audiences through the media?

18. Do you think it is important to train scientists to be able to communicate their research results to the lay public and to policymakers in a simple manner? (Yes/No/Not sure)

19. Give reasons for your answer above.

20. If, at present, science is not being communicated to the public, what happens to research findings generated by the scientists at your university?

21. Identify challenges that academics encounter in the process of public science communication. 
Agnella, S., De Bortoli, A., Scamuzzi, S., L'Astorina, A., Cerbara, L., Valente, A. and Avveduto, S. (2012). 'How and why the scientists communicate with society: The case of physics in Italy'. In: Proceedings of the PCST Conference 2012. Florence, Italy.

Andrews, E., Weaver, A., Hanley, D., Shamatha, J. H. and Melton, G. (2005). 'Scientists and public outreach: Participation, motivations, and impediments'. Journal of Geoscience Education 53 (3), pp. 281-293. URL: http: //serc . carleton .edu/files/nagt/jge/abstracts/Andrews_v53n3p281.pdf.

Bakyawa, J., Devlin, M., Serwadda, D. and IJsselmuiden, C. (2013). 'Implementing a health research communication program in a low resource country: Experience from Uganda's Makerere University School of Public'. Scholarly and Research Communication 4 (2), pp. 1-20.

URL: http://src-online.ca/index.php/src/article/view/103.

Baram-Tsabari, A. and Lewenstein, B. V. (2013). 'An Instrument for Assessing Scientists' Written Skills in Public Communication of Science'. Science Communication 35 (1), pp. 56-85. DOI: 10.1177/1075547012440634.

Baron, N. (2010). 'Stand up for science'. Nature 468 (7327), pp. 1032-1033. DOI: $10.1038 / 4681032$ a.

Bauer, M. and Jensen, P. (2011). 'The mobilization of scientists for public engagement'. Public Understanding of Science 20 (1), pp. 3-11. DOI: $10.1177 / 0963662510394457$.

BBSRC (Biotechnology and Biological Sciences Research Council) (2014). Public Engagement and Science Communication Survey. Swindon, U.K.

Bentley, P. and Kyvik, S. (2011). 'Academic staff and public communication: A survey of popular science publishing across 13 countries'. Public Understanding of Science 20 (1), pp. 48-63. DOI: 10.1177/0963662510384461.

Besley, J. C. and Nisbet, M. (2011). 'How scientists view the public, the media and the political process'. Public Understanding of Science 22 (6), pp. 644-659. DOI: $10.1177 / 0963662511418743$.

Besley, J. C., Oh, S. H. and Nisbet, M. (2013). 'Predicting scientists' participation in public life'. Public Understanding of Science 22 (8), pp. 971-987. DOI: 10.1177/0963662512459315. PMID: 23825262.

Besley, J. C. and Tanner, A. H. (2011). 'What Science Communication Scholars Think About Training Scientists to Communicate'. Science Communication 33 (2), pp. 239-263. DOI: 10.1177/1075547010386972.

Besley, J. C., Dudo, A. D., Yuan, S. and Ghannam, N. A. (2016). 'Qualitative Interviews With Science Communication Trainers About Communication Objectives and Goals'. Science Communication 38 (3), pp. 356-381. DOI: $10.1177 / 1075547016645640$.

Bond, R. and Paterson, L. (2005). 'Coming down from the Ivory Tower? Academics' Civic and Economic Engagement with the Community'. Oxford Review of Education 31 (3), pp. 331-351.

Brossard, D. and Lewenstein, B. V. (2010). 'A Critical Appraisal of Models of Public Understanding of Science: Using Practice to Inform Theory'. In: Communicating Science; New Agendas in Communication. Ed. by L. Kahlor and P. A. Stout. New York, U.S.A.: Routledge, Taylor \& Francis, pp. 11-39.

Burchell, K., Franklin, S. and Holden, K. (2009). Public culture as professional science. Final report of the ScoPE project (Scientists on public engagement: from communication to deliberation?) London, U.K.: BIOS (Centre for the Study of Bioscience, Biomedicine, Biotechnology, Society) and London School of Economics. URL: http://eprints. Ise .ac.uk/37115/. 
Burchell, K. (2007). 'Empiricist selves and contingent "others": the performative function of the discourse of scientists working in conditions of controversy'. Public Understanding of Science 16 (2), pp. 145-162.

DOI: $10.1177 / 0963662507060587$.

- (2015). Factors affecting public engagement by researchers: Literature review. London, U.K.: Science Policy Institute, University of Westminster.

Casini, S. and Neresini, F. (2013). 'Behind Closed Doors. Scientists' and Science Communicators' Discourses on Science in Society. A Study Across European Research Institutions'. Tecnoscienza 3 (2), pp. 37-62.

URL: http://www. tecnoscienza.net/index.php/tsj/article/view/113.

Claassen, G. (2011). 'Science and the media in South Africa: Reflecting a 'dirty mirror". Communicatio 37 (3), pp. 351-366.

DOI: $10.1080 / 02500167.2011 .622288$.

Coleman, A. (2012). 'Towards delivering e-health education using Public Internet Terminals (PIT) systems in rural communities in South Africa'. JCOM 11 (04), A01. URL: https://jcom.sissa.it/archive/11/04/Jcom1104\%282012\%29A01.

Corley, E. A., Kim, Y. and Scheufele, D. A. (2011). 'Leading US nano-scientists' perceptions about media coverage and the public communication of scientific research findings'. Journal of Nanoparticle Research 13 (12), pp. 7041-7055. DOI: $10.1007 / \mathrm{s} 11051-011-0617-3$.

Crettaz von Roten, F. (2011). 'Gender Differences in Scientists' Public Outreach and Engagement Activities'. Science Communication 33 (1), pp. 52-75.

DOI: $10.1177 / 1075547010378658$.

Crettaz von Roten, F. and Goastellec, G. (2015). 'Understanding academics' popular science publishing: Institution culture and management style effects'. Journal for New Generation Science 13 (2), pp. 15-29.

Dang, L. and Russo, P. (2015). 'How astronomers view education and public outreach: An exploratory study'. Communicating Astronomy with the Public Journal 18, pp. 16-21. arXiv: 1507.08552.

URL: http://www . capjournal .org/issues/18/18_16.php (visited on 21st November 2016).

Davies, S. R. (2008). 'Constructing communication: Talking to scientists about talking to the public'. Science Communication 29 (4), pp. 413-434.

- (2013). 'Constituting Public Engagement: Meanings and Genealogies of PEST in Two U.K. Studies'. Science Communication 35 (6), pp. 687-707. DOI: $10.1177 / 1075547013478203$.

Department of Science and Technology (2014). Science engagement framework. Pretoria, South Africa.

DeRosier, C., Sulemana, I., James, H. S., Valdivia, C., Folk, W. and Smith, R. D. (2015). 'A comparative analysis of media reporting of perceived risks and benefits of genetically modified crops and foods in Kenyan and international newspapers'. Public Understanding of Science 24 (5), pp. 563-581. DOI: $10.1177 / 0963662514568061$.

DRUSSA (Development Research Uptake in Sub-Saharan Africa) (2015). About DRUSSA. URL: www .drussa. net (visited on 3rd May 2016).

Dudo, A. (2013). 'Toward a Model of Scientists' Public Communication Activity The Case of Biomedical Researchers'. Science Communication 35 (4), pp. 476-501. DOI: $10.1177 / 1075547012460845$.

Dudo, A. and Besley, J. C. (2016). 'Scientists' Prioritization of Communication Objectives for Public Engagement'. PLOS ONE 11 (2), e0148867, pp. 1-18. DOI: 10.1371/journal.pone.0148867. 
Dudo, A., Kahlor, L., AbiGhannam, N., Lazard, A. and Liang, M.-C. (2014). 'An analysis of nanoscientists as public communicators'. Nature Nanotechnology 9 (10), pp. 841-844. DOI: 10.1038/nnano. 2014.194.

Dunwoody, S., Brossard, D. and Dudo, A. (2009). 'Socialization or Rewards? Predicting U.S. Scientist-Media Interactions'. Journalism $\mathcal{E}$ Mass Communication Quarterly 86 (2), pp. 299-314. DOI: 10.1177/107769900908600203.

EC (European Commission) (2007). European research in the media: The researcher's point of view. URL: https://ec . europa. eu/research/conferences/2007/bcn20 07/researchers_en.pdf (visited on 3rd May 2016).

Ecklund, E. H., James, S. A. and Lincoln, A. E. (2012). 'How Academic Biologists and Physicists View Science Outreach'. PLoS ONE 7 (5), e36240. DOI: 10.1371 /journal . pone. 0036240.

Einsiedel, E. (2014). 'Publics and their participation in science and technology: Changing roles, blurring boundaries'. In: Routledge Handbook of Public Communication of Science and Technology. Ed. by M. Bucchi and B. Trench. 2nd ed. London, U.K. and New York, U.S.A.: Routledge, pp. 125-139.

Ekanem, I. A. (2003). 'Communicating Science Information in a Science-Unfriendly Environment: The Experience of Nigeria'. Public Understanding of Science 12 (2), pp. 203-209. DOI: 10.1177/09636625030122005.

Entradas, M. and Bauer, M. M. (2016). 'Mobilisation for public engagement: Benchmarking the practices of research institutes'. Public Understanding of Science. DOI: 10.1177/0963662516633834.

Fish, D., Allie, S., Pelaez, N. and Anderson, T. (2016). 'A cross-cultural comparison of high school students' responses to a science centre show on the physics of sound in South Africa'. Public Understanding of Science, p. 0963662516642725. DOI: 10.1177/0963662516642725. PMID: 27117487.

France, B., Cridge, B. and Fogg-Rogers, L. (2015). 'Organisational Culture and Its Role in Developing a Sustainable Science Communication Platform'. International Journal of Science Education, Part B, pp. 1-15. DOI: $10.1080 / 21548455.2015 .1106025$.

Gascoigne, T. and Metcalfe, J. (1997). 'Incentives and Impediments to Scientists Communicating Through the Media'. Science Communication 18 (3), pp. 265-282. DOI: $10.1177 / 1075547097018003005$.

Gastrow, M. (2015). 'Science and the Social Media in an African Context The Case of the Square Kilometre Array Telescope'. Science Communication 37 (6), pp. 703-722. DOI: $10.1177 / 1075547015608637$.

Gething, L. (2003). "Them and us': scientists and the media-attitudes and experiences'. South African Medical Journal 93 (3), pp. 197-201. PMID: 12768943.

Gieryn, T. F. (1983). 'Boundary-Work and the Demarcation of Science from Non-Science: Strains and Interests in Professional Ideologies of Scientists'. American Sociological Review 48 (6), pp. 781-795. DOI: 10.2307/2095325.

Grand, A., Davies, G., Holliman, R. and Adams, A. (2015). 'Mapping public engagement with research in a UK University'. PLOS ONE 10 (4), e0121874, pp. 1-19. DOI: 10.1371/journal . pone.0121874. PMID: 25837803.

Greenwood, M. R. C. and Riordan, D. G. (2001). 'Civic Scientist/Civic Duty'. Science Communication 23 (1), pp. 28-40. DOI: 10.1177/1075547001023001003.

Heleta, S. (2016). 'Academics can change the world - if they stop talking only to their peers. Africa edition'. URL: https://theconversation. com/academics-ca n-change-the-world-if-they-stop-talking-only-to-their-peers-55713 (visited on 6th June 2016). 
Holland, B. A. (1999). 'Factors and strategies that influence faculty involvement in public service'. Journal of Public Service and Outreach 4 (1), pp. 37-44.

Holliman, R., Adams, A., Blackman, T., Collins, T., Davies, G., Dibb, S., Grand, A., Holti, R., McKerlie, F., Mahony, N. and Wissenburg, A. (2015). An open research university: final report. Milton Keynes, U.K.: The Open University. URL: http://oro. open. ac.uk/44255/.

Horst, M. (2013). 'A Field of Expertise, the Organization, or Science Itself? Scientists' Perception of Representing Research in Public Communication'. Science Communication 35 (6), pp. 758-779. DOI: 10.1177/1075547013487513.

Ipsos MORI (2001). The role of scientists in public debate.

URL: https://www.ipsos-mori.com/researchpublications/researcharchive /1694/The-Role-Of-Scientists-In-Public-Debate.aspx (visited on 17th May 2016).

Jacobson, N., Butterill, D. and Goering, P. (2004). ‘Organizational Factors that Influence University-Based Researchers' Engagement in Knowledge Transfer Activities'. Science Communication 25 (3), pp. 246-259. DOI: $10.1177 / 1075547003262038$.

Jensen, P. (2011). 'A statistical picture of popularization activities and their evolutions in France'. Public Understanding of Science 20 (1), pp. 26-36. DOI: $10.1177 / 0963662510383632$.

Jensen, P., Rouquier, J. B., Kreimer, P. and Croissant, Y. (2008). 'Scientists who engage with society perform better academically'. Science and Public Policy 35 (7), pp. 527-541.

Johnson, D. R., Ecklund, E. H. and Lincoln, A. E. (2014). 'Narratives of Science Outreach in Elite Contexts of Academic Science'. Science Communication 36 (1), pp. 81-105. DOI: 10.1177/1075547013499142.

Karikari, T. K., Yawson, N. A. and Quansah, E. (2016). 'Developing Science Communication in Africa: Undergraduate and Graduate Students should be Trained and Actively Involved in Outreach Activity Development and Implementation'. Journal of undergraduate neuroscience education: JUNE: a publication of FUN, Faculty for Undergraduate Neuroscience 14 (2), E5-E8. PMID: 27385932.

Khanna, J. (2001). 'Science Communication in Developing Countries: Experience from WHO Workshops'. Science Communication 23 (1), pp. 50-56. DOI: $10.1177 / 1075547001023001005$.

Koh, E. J., Dunwoody, S., Brossard, D. and Allgaier, J. (2016). 'Mapping Neuroscientists Perceptions of the Nature and Effects of Public Visibility'. Science Communication 38 (2), pp. 170-196. DOI: 10.1177/1075547016635180.

Kreimer, P., Levin, L. and Jensen, P. (2011). ‘Popularization by Argentine researchers: the activities and motivations of CONICET scientists'. Public Understanding of Science 20 (1), pp. 37-47. DOI: 10.1177/0963662510383924.

Kyvik, S. (2005). 'Popular science publishing and contributions to public discourse among university faculty'. Science Communication 26 (3), pp. 288-311.

Lévy-Leblond, J.-M. (1992). 'About misunderstandings about misunderstandings'. Public Understanding of Science 1 (1), pp. 17-22. DOI: $10.1088 / 0963-6625 / 1 / 1 / 004$.

Liang, X., Su, L. Y.-F., Yeo, S. K., Scheufele, D. A., Brossard, D., Xenos, M., Nealey, P. and Corley, E. A. (2014). 'Building Buzz: (Scientists) Communicating Science in New Media Environments'. Journalism \& Mass Communication Quarterly 91 (4), pp. 772-791. DOI: $10.1177 / 1077699014550092$. 
Lo, Y.-Y. (2016). 'Online communication beyond the scientific community: Scientists' use of new media in Germany, Taiwan and the United States to address the public'. Ph.D. dissertation. Free University of Berlin.

Lo, Y.-Y. and Peters, H. P. (2015). "Taiwanese life scientists less "medialized" than their Western colleagues'. Public Understanding of Science (Bristol, England) 24 (1), pp. 6-22. DOI: 10.1177/0963662513513863. PMID: 24368762.

- (2016). 'Blogging by scientists: A rare and peripheral activity'. In: Proceedings of the PCST Conference 2016. Istanbul, Turkey.

Marcinkowski, F., Kohring, M., Furst, S. and Friedrichsmeier, A. (2014). 'Organizational Influence on Scientists' Efforts to Go Public: An Empirical Investigation'. Science Communication 36 (1), pp. 56-80. DOI: $10.1177 / 1075547013494022$.

Martín-Sempere, M. J., Garzón-García, B. and Rey-Rocha, J. (2008). 'Scientists' motivation to communicate science and technology to the public: surveying participants at the Madrid Science Fair'. Public Understanding of Science 17 (3), pp. 349-367. DOI: $10.1177 / 0963662506067660$.

Massarani, L. (2015). 'Voices from other lands'. Public Understanding of Science 24 (1), pp. 2-5. DOI: $10.1177 / 0963662514563888$.

Miller, J. D. (1998). 'The measurement of civic scientific literacy'. Public Understanding of Science 7 (3), pp. 203-223. DOI: 10.1088/0963-6625/7/3/001.

Mizumachi, E., Matsuda, K., Kano, K., Kawakami, M. and Kato, K. (2011). 'Scientists' attitudes toward a dialogue with the public: a study using "science cafes"'. JCOM 10 (04), A02.

URL: https://jcom.sissa.it/archive/10/04/Jcom1004\%282011\%29A02.

Mutheu, J. and Wanjala, R. (2009). 'The public, parasites and coffee: the Kenyan Science Café concept'. Trends in Parasitology 25 (6), p. 245. DOI: $10.1016 / j$.pt.2009.03.002.

Nadkarni, N. M. and Stasch, A. E. (2013). 'How broad are our broader impacts? An analysis of the National Science Foundation's Ecosystem Studies Program and the Broader Impacts requirement'. Frontiers in Ecology and the Environment 11 (1), pp. 13-19. DOI: $10.1890 / 110106$.

Neresini, F. and Bucchi, M. (2011). 'Which indicators for the new public engagement activities? An exploratory study of European research institutions'. Public Understanding of Science 20 (1), pp. 64-79. DOI: $10.1177 / 0963662510388363$.

NUST (National University of Science and Technology) (2011/2012). National University of Science and Technology Yearbook 19. Bulawayo, Zimbabwe: Information and Public Relations Office.

- (2013). National University of Science and Technology Research Policy. Bulawayo, Zimbabwe: Research and Innovation Office.

Nyirenda, D., Makawa, T. C., Chapita, G., Mdalla, C., Nkolokosa, M., Obyrne, T., Heyderman, R. and Desmond, N. (2016). 'Public engagement in Malawi through a health-talk radio programme 'Umoyo nkukambirana': A mixed-methods evaluation'. Public Understanding of Science. DOI: $10.1177 / 0963662516656110$.

Parliament of Zimbabwe (1990). National University of Science and Technology Act 25:13. URL: http://www .parlzim.gov.zw/acts-list/national-university-of -science-and-technology-act-25-13 (visited on 3rd May 2016).

Parsons, W. (2001). 'Scientists and politicians: The need to communicate'. Public Understanding of Science 10 (3), pp. 303-314. DOI: 10 .1088/0963-6625/10/3/304. 
Peters, H. P. (2013). 'Gap between science and media revisited: Scientists as public communicators'. Proceedings of the National Academy of Sciences 110 (Supplement 3), pp. 14102-14109. DOI: 10.1073/pnas .1212745110. PMID: 23940312.

Peters, H. P., Dunwoody, S., Allgaier, J., Lo, Y.-Y. and Brossard, D. (2014). 'Public communication of science 2.0: Is the communication of science via the "new media" online a genuine transformation or old wine in new bottles?' EMBO reports 15 (7), pp. 749-753. DOI: 10.15252/embr.201438979. PMID: 24920610.

Poliakoff, E. and Webb, T. L. (2007). 'What factors predict scientists' Intentions to participate in public engagement of science activities?' Science Communication 29 (2), pp. 242-263.

Ren, F., Liu, X., Wang, X. and Yin, L. (2014). 'Comparison study on China-UK scientists' engagement in public outreach activities'. In: Proceedings of PICMET '14 Conference: Portland International Center for Management of Engineering and Technology; Infrastructure and Service Integration, pp. 429-434.

Research Councils UK (2010). Concordat for Engaging the Public with Research. URL: http://www.rcuk.ac.uk/pe/Concordat/ (visited on 17th March 2016).

SARIMA (Southern African Research and Innovation Management Association) (2015). Leadership in research and innovation management. URL: http: //www . sarima. co .za (visited on 3rd May 2016).

Searle, S. D. (2011). 'Scientists' communication with the general public: An Australian survey'. Ph.D. dissertation. The Australian National University.

- (2013). 'Scientists' engagement with the public'. In: Communication and Engagement with Science and Technology: Issues and Dilemmas. A Reader in Science Communication. Ed. by J. K. Gilbert and S. M. Stocklmayer. London, U.K. and New York, U.S.A.: Routledge, pp. 41-58. URL: https : //www . routledg e.com/Communication-and-Engagement-with-Science-and-Technology-Issu es-and-Dilemmas/Gilbert-Stocklmayer/p/book/9780415896269.

Silva, J. and Bultitude, K. (2009). 'Best practice in communications training for public engagement with science, technology, engineering and mathematics'. JCOM 08 (02), A03. URL: https://jcom. sissa.it/archive/08/02/Jcom0802\%282009\%29A03.

Skrip, M. M. (2015). 'Crafting and evaluating Broader Impact activities: a theory-based guide for scientists'. Frontiers in Ecology and the Environment 13 (5), pp. 273-279. DOI: $10.1890 / 140209$.

Smith, B., Baron, N., English, C., Galindo, H., Goldman, E., McLeod, K., Miner, M. and Neeley, E. (2013). 'COMPASS: Navigating the Rules of Scientific Engagement'. PLoS Biology 11 (4), e1001552.

DOI: $10.1371 /$ journal pbio. 1001552.

Stilgoe, J., Lock, S. J. and Wilsdon, J. (2014). 'Why should we promote public engagement with science?' Public Understanding of Science 23 (1), pp. 4-15. DOI: $10.1177 / 0963662513518154$.

Stocklmayer, S. M. (2001). 'The background to effective science communication with the public'. In: Science Communication in Theory and Practice. Ed. by S. M. Stocklmayer, M. M. Gore and C. Bryant. Dordrecht, the Netherlands: Kluwer Academic Publishers, pp. 3-22.

Sturzenegger-Varvayanis, S., Eosco, G., Ball, S., Lee, K., Halpern, M. and Lewenstein, B. (2008). 'How university scientists view science communication to the public'. In: Proceedings of the PCST Conference 2008. Malmö, Sweden.

Suleski, J. and Ibaraki, M. (2010). 'Scientists are talking, but mostly to each other: a quantitative analysis of research represented in mass media'. Public Understanding of Science 19 (1), pp. 115-205. DOI: 10.1177/0963662508096776. 
Tan Wee Hin, L. and Subramaniam, R. (2014). 'Challenges Facing Developing Countries in Communicating Science to the Public'. In: Communicating Science to the Public: Opportunities and challenges for the Asia-Pacific region. Ed. by L. Tan Wee Hin and R. Subramaniam. Dordrecht, Netherlands: Springer, pp. 213-222. URL: http://link. springer.com/10.1007/978-94-017-9097-0_13.

The Pew Research Center for the People and the Press (2009). Public praises science; scientists fault public, media. URL: https://www. upf.edu/pcstacademy/_docs/Pe w-Science_Survey_2009.pdf (visited on 29th June 2016).

The Royal Society (2006). Survey of factors affecting science communication by scientists and engineers. London, U.K.: The Royal Society. URL: https://royal society.org/topics-policy/publications/2006/science-communication/ (visited on 3rd May 2016).

TNS BMRB (2015). Factors affecting public engagement by researchers: A study on behalf of a consortium of UK public research funders. URL: https://well come . ac . uk/news /what-are-barriers-uk-researchers-engaging-public (visited on 3rd May 2016).

Torres-Albero, C., Fernandez-Esquinas, M., Rey-Rocha, J. and Martin-Sempere, M. J. (2011). 'Dissemination practices in the Spanish research system: scientists trapped in a golden cage'. Public Understanding of Science 20 (1), pp. 12-25. DOI: 10.1177/0963662510382361.

Treise, D. and Weigold, M. F. (2002). 'Advancing Science Communication: A Survey of Science Communicators'. Science Communication 23 (3), pp. 310-322. DOI: $10.1177 / 107554700202300306$.

Tsfati, Y., Cohen, J. and Gunther, A. C. (2011). 'The influence of presumed media influence on news about science and scientists'. Science Communication 33 (2), pp. 143-166. DOI: $10.1177 / 1075547010380385$.

University of Kassel (2008). Changing academic profession: An international research project.

URL: https://www . uni-kassel.de/einrichtungen/incher/forschung/wissen schaftlicher-wandel/cap-the-changing-academic-profession.html (visited on 3rd May 2016).

van der Sanden, M. C. A. and Meijman, F. J. (2008). 'Dialogue guides awareness and understanding of science: an essay on different goals of dialogue leading to different science communication approaches'. Public Understanding of Science 17 (1), pp. 89-103. DOI: 10.1177/0963662506067376.

Vetenskap and Allmänhet (2003). How researchers view public and science. URL: https://v-a.se/2004/01/how-researchers-view-public-and-science2003-interview-survey/ (visited on 3rd May 2016).

Watermeyer, R. (2015). 'Lost in the 'third space': the impact of public engagement in higher education on academic identity, research practice and career progression'. European Journal of Higher Education 5 (3), pp. 331-347. DOI: $10.1080 / 21568235.2015 .1044546$.

Whitmer, A., Ogden, L., Lawton, J., Sturner, P., Groffman, P. M., Schneider, L., Hart, D., Halpern, B., Schlesinger, W., Raciti, S., Bettez, N., Ortega, S., Rustad, L., Pickett, S. T. and Killilea, M. (2010). 'The engaged university: providing a platform for research that transforms society'. Frontiers in Ecology and the Environment 8 (6), pp. 314-321. DOI: 10.1890/090241.

Wigren-Kristoferson, C., Gabrielsson, J. and Kitagawa, F. (2011). 'Mind the gap and bridge the gap: research excellence and diffusion of academic knowledge in Sweden'. Science and Public Policy 38 (6), pp. 481-492.

DOI: $10.3152 / 030234211 \mathrm{X} 12960315267859$. 
Wilcox, C. (2012). ‘Guest Editorial. It's Time To e-Volve: Taking Responsibility for Science Communication in a Digital Age'. The Biological Bulletin 222 (2), pp. 85-87. DOI: 10.1086/BBLv222n2p85.

Wright, A. J. (2015). 'Defending the Ivory Tower against the end of the world'. Journal of Environmental Studies and Sciences 5 (1), pp. 66-69. DOI: $10.1007 / \mathrm{s} 13412-015-0227-\mathrm{y}$.

Young, N. and Matthews, R. (2007). 'Experts' understanding of the public: knowledge control in a risk controversy'. Public Understanding of Science 16 (2), pp. 123-144. DOI: 10.1177/0963662507060586.

Heather Ndlovu completed this study as part of her M.Phil. degree in Science and Technology Studies at Stellenbosch University, South Africa (2015). She also holds an honours degree in Library and Information Science, as well as a postgraduate Diploma in Higher Education, from the National University of Science and Technology in Zimbabwe. She is the current management officer in the field of research uptake at NUST, and also lectures in records and archives management. E-mail: heatherndlovu@gmail.com.

Marina Joubert is a science communication researcher and lecturer at CREST (Centre for Research on Evaluation, Science and Technology) at Stellenbosch University, South Africa, where she is part of a research team linked to the South African Research Chair in Science Communication. She holds a B.Sc. Food Science (Honours) degree, as well as a Journalism (honours) degree from Stellenbosch University, as well as an M.Sc. (Agric) from University of Pretoria. She is currently doing research on the factors affecting the public engagement behaviour of South African research leaders. E-mail: marinajoubert@sun.ac.za.

Nelius Boshoff (Ph.D.) is a Senior Lecturer at the Centre for Research on Evaluation, Science and Technology (CREST) at Stellenbosch University, South Africa, host of the DST-NRF Centre of Excellence in Scientometrics and STI Policy (SciSTIP). His professional interests include studies of research collaboration and research impact (with a focus on the societal impact of research), as well as bibliometrics with a focus on Africa. E-mail: scb@sun.ac.za.

\section{How to cite}

Ndlovu, H., Joubert, M. and Boshoff, N. (2016). 'Public science communication in Africa: views and practices of academics at the National University of Science and Technology in Zimbabwe'. JCOM 15 (06), A05. 